\title{
Self-efficacy, mental models and team adaptation: A first approach on football and futsal refereeing
}

\author{
João Aragão e Pina ${ }^{\text {a, *, Ana Margarida Passos }}{ }^{\mathrm{b}}$, M. Travis Maynard ${ }^{\mathrm{c}}$, Jorge Sinval ${ }^{\mathrm{b}, \mathrm{d} \text {, e }}$ \\ ${ }^{a}$ ISCTE - Instituto Universitário de Lisboa, Lisbon, Av. Forças Armadas, 1649-026, Portugal \\ ${ }^{\mathrm{b}}$ Business Research Unit (BRU-IUL), Instituto Universitário de Lisboa (ISCTE-IUL), Lisbon, Av. Forças Armadas, 1649-026, Portugal \\ ${ }^{\mathrm{c}}$ Department of Management, College of Business, Colorado State University, Fort Collins, CO, 211 Rockwell Hall, USA \\ ${ }^{\mathrm{d}}$ William James Center for Research, ISPA - Instituto Universitário, Lisbon, Av. Forças Armadas, 1649-026, Portugal \\ ${ }^{\text {e }}$ Faculty of Philosophy, Sciences and Languages of Ribeirão Preto, University of São Paulo, Ribeirão Preto - SP, Av. Bandeirantes, 3900, 14040-901, Brazil
}

\section{A R T I C L E I N F O}

\section{Keywords:}

Football referees

Futsal referees

Self-efficacy

Mental models

Team adaptation

\begin{abstract}
A B S T R A C T
Objective: Within the football and futsal refereeing context, even though referees work within teams, there is very little research considering the implications of team dynamics. In response, this study starts to address this gap in the literature by investigating the moderating effect of mental models on the relationship between self-efficacy beliefs and perceptions of team adaptation within the exciting context of professional and national football and futsal refereeing.

Design: We obtained online questionnaires from 339 active football and futsal referees within the National and Professional league at two distinct points (April and May) within the football season.

Results: Self-efficacy beliefs were positively associated with perceptions of team adaptation (only for football referees). Mental models were positively associated with team adaptation. Likewise, the moderation between mental models and self-efficacy beliefs was positively associated with perceptions of team adaptation. However, such an effect was only significant at the futsal referees' level.

Conclusion: This study emphasises the importance of mental models for team adaptation and the importance of self-efficacy beliefs in predicting perceptions of team adaptation. We hope that this study represents the first step in a greater appreciation of the salience of team dynamics and their impact on football and futsal referees' performance and that future research can build upon our work.
\end{abstract}

\section{Introduction}

In recent times, football (or "soccer", or association football) has become an industry that generates massive financial rewards (e.g., Alarcon, Duran, \& Guajardo, 2014; KPMG, 2016; Svantesson, 2014). As a result, the sport of football has expanded to include other forms of the sport such as futsal, which is also increasing in popularity around the globe (Moore, Bullough, Goldsmith, \& Edmondson, 2014). Futsal is played worldwide, and it is considered an indoor game with the fastest development in the world (Cosmin \& Mircea, 2014; Moore et al., 2014). While the players themselves get much of the attention, there are other participants on the field that also play an essential role - the referees. Given their importance, increasing attention is being given to the referees since their decisions not only impact the play on the field but also have a significant financial and social impact on clubs or national teams (Can, Bayansalduz, Soyer, \& Pacali, 2014; Slack, Maynard, Butt, \& Olusoga, 2015; Webb, Wagstaff, Rayner, \& Thelwell, 2016).

As a result of the increasing awareness regarding the role of football referees, research on this topic has become more prevalent in the literature. A recent integrative review showed that $95.88 \%$ of the peerreviewed publications addressing football referee performance were published after 2001 (Aragão e Pina, Passos, Araújo, \& Maynard, 2018). It is also interesting to note that even though referees perform their duties within the context of teams, and their decisions are based on teamwork (see Helsen \& Bultynck, 2004), to date, only one study has addressed the entire football refereeing team (see Boyer, Rix-Lièvre, \& Récopé, 2015). Considering futsal referees, and despite the increasing

\footnotetext{
* Corresponding author.

E-mail addresses: joao.paulo.pina@iscte-iul.pt (J. Aragão e Pina), ana.passos@iscte-iul.pt (A.M. Passos), travis.maynard@business.colostate.edu (M.T. Maynard), jorgesinval@gmail.com (J. Sinval).
} 
interest in this sport, there is limited published research in peer-reviewed journals, and scarce literature about futsal refereeing (Ahmed, Davison, \& Dixon, 2017; Moore et al., 2014). We searched several databases (PsycINFO; PubPsych; Scopus; Web of Science), and we only found one study addressing the stress level of futsal referees (Londrina, 2018) and four other studies concerning the activity profile and physiological demands of futsal referees (Ahmed et al., 2017; Dixon, 2014a, 2014b; Rebelo et al., 2011).

While research has considered the factors that shape individual referee performance (Aragão e Pina, Passos, Carvalho, \& Maynard, 2019; MacMahon, Helsen, Starkes, \& Weston, 2007; Mathers \& Brodie, 2011), there has not been sufficient consideration of the team as a collective, which is intriguing considering, for example, the implementation of the video assistant referees (VAR) (Boyer, MacMahon, Recopé, \& Rix-Lièvre, 2020). The increasing number of elements per refereeing team may influence teamwork processes and team performance (Aragão e Pina et al., 2018; Boyer et al., 2020; Dohmen \& Sauermann, 2015; LePine, Piccolo, Jackson, Mathieu, \& Saul, 2008). Likewise, given the fact that refereeing is highly demanding and takes place within dynamic contexts, the refereeing team's performance depends on several factors such as the individual and team's ability to adapt (Araújo, Davids, \& Hristovski, 2006; Burke, Stagl, Salas, Pierce, \& Kendall, 2006; Marques-Quinteiro, Ramos-Villagrasa, Passos, \& Curral, 2015; Maynard, Kennedy, \& Sommer, 2015). For instance, the assistant referee decision may be influenced by his preoccupation about the main referee decision-making process (Boyer et al., 2020).

Football and futsal referees need to adapt to several constraints such as the type of the competition (e.g., world cup, international game, national game), the importance of the game (e.g., clubs' participants, broadcasting), the stadiums where the game takes place (e.g., type of the pitch, fans reputation, number of spectators), the composition of the refereeing team, since it is not always a fixed team (e.g., number of individuals, reputation, experience, nationality, personality), the game itself (e.g., pace, teams' changing tactics caused by the score of the game, players' reaction), the weather conditions, the adequate functioning of the VAR or the audio communicating system, just to cite a few common examples (see Boyer et al., 2020; Diotaiuti, Falese, Mancone, \& Purromuto, 2017; Myers, Feltz, Guillén, \& Dithurbide, 2012; Unkelbach \& Memmert, 2008). However, we know very little about what shapes a referee team's ability to adapt within the context of football and futsal - a gap we address in the current study.

Interestingly, team adaptation has not been examined within football or futsal refereeing; even though, in a recent study, top-level referees considered adaptability an essential factor for refereeing excellence (Aragão e Pina et al., 2019). That said; there is a wealth of research examining team adaptation in other contexts (see Baard, Rench, \& Kozlowski, 2015; Maynard et al., 2015), which can be used as a foundation for starting to consider team adaptation in football and futsal refereeing. We define team adaptation process "as adjustments to relevant team processes (i.e., action, interpersonal, transition) in response to the disruption or trigger giving rise to the need for adaptation" (Maynard et al., 2015, p. 656). The referee team adapts when individual members (and the team as a whole) alter the way they are working to respond to relevant triggers to the game.

According to the literature, good team adaptation can be achieved through different cognitive processes and states such as efficacy beliefs and shared cognitions about the task (Burke et al., 2006). For instance, self-efficacy, defined by Bandura (1997) as the belief an individual has in being able to execute a specific task to achieve a particular outcome, is an individual-level cognitive factor that is essential for the adaptation process (Kozlowski et al., 2001; Maddux, 1995), either at the individual-level or team-level (Griffin \& Hesketh, 2003; LePine, 2003; Pulakos et al., 2002). While self-efficacy is widely studied in sport and exercise contexts (Guillén, Feltz, Gilson, \& Dithurbide, 2019), research on football refereeing has started to develop with the conceptual work of Guillén and Feltz (2011) that stimulated the development and adaptation of the Referee Self-Efficacy Scale (REFS) to different countries (Eskiyecek, Satici, Ozaltas, Savucu, \& Gul, 2019; Guillén et al., 2019; Karaçam \& Pulur, 2017; Labudek et al., 2019; Myers et al., 2012). Nevertheless, the study of self-efficacy as a predictor of adaptation is a novel contribution to the football and futsal refereeing team literature.

Mental models, defined as "organised mental representations of the key elements within a team's relevant environment that are shared across team members (Mohammed, Ferzandi, \& Hamilton, 2010) have been used to explain team adaptation and ultimately team's performance (Maynard et al., 2015). Mental models are essential for refereeing teams because they face non-routine tasks (Marks, Zaccaro, \& Mathieu, 2000), they must coordinate tasks such as travelling and game preparation, according to the game they are appointed to (Hancock, Martin, Evans, \& Paradis, 2018; Samuel, 2015), they must share technical and tactical knowledge to perform adequately (Hancock et al., 2018; Mallo, Frutos, Juárez, \& Navarro, 2012; Mascarenhas, O’Hare, \& Plessner, 2006; McEwan \& Beauchamp, 2014), they must anticipate other members' needs and actions and adapt their behaviours concerning the task demands and the other members (Cannon-Bowers, Salas, \& Converse, 1993; Hancock et al., 2018), among many other actions that need reasoning, decision-making and behaviour (Jones, Ross, Lynam, Perez, \& Leitch, 2011). However, we know very little about the influence of these variables on referee teams in football and futsal.

Considering the existing gap in the literature and following the suggestions made by Aragão e Pina et al. (2018), concerning the necessity to differentiate samples in refereeing studies, the present study is a novel contribution to the futsal refereeing literature. Accordingly, we draw from the broader teamwork literature and leverage both individual- and team-level factors to gain a more detailed understanding of the factors that shape referee team adaptation. Additionally, we examine how mental models (a team-level cognitive factor) also shape perceptions of team adaptation and how mental models moderate the relationship between self-efficacy beliefs and perceptions of team adaptation. We also investigated whether this model works similarly for soccer and futsal referee teams. Our study aims to account for the influence of individual cognitions on team adaptation while recognising the relevance of team phenomena perceptions.

\section{Background and theoretical development}

Within the context of refereeing, referee teams need to adapt quickly and appropriately to dynamic changes, adjust their cognitive and behavioural processes, and evaluate and analyse the situations in short periods (Burke et al., 2006; Hancock et al., 2018; Rosen et al., 2011). Team adaptation has received little or no attention in professional football and futsal refereeing research, however, the topic has been studied within the context of organisational settings (Baard et al., 2015; Burke et al., 2006; LePine, 2005; Maynard et al., 2015; Rosen et al., 2011) but, surprisingly, a clear conceptualisation of this construct is claimed by several authors (Baard et al., 2015; Maynard et al., 2015). Since the literature has considered a multitude of ways that teams can adapt (i.e., either general in nature or specific), in the present study, we follow the framework proposed by Maynard et al. (2015). This framework is based on the input-mediator-outcome (IMO) framework of Ilgen, Hollenbeck, Johnson, and Jundt (2005), that considers team adaptability as an input variable or antecedent to team adaptation; team adaptation process is viewed as a mediator or a process variable; and team adaptative outcome as an outcome, such as effectiveness, performance, or affective reactions of team members. As input variables, Maynard and colleagues (2005) consider three levels of analysis, namely individual-level, team-level (both of which will be included here) and organisational-level, which will be outside of the focus of this study.

The literature on team adaptation has predominantly focused its attention on the relationship between adaptation and various outcomes such as performance (Dechurch \& Haas, 2008; Gorman, Cooke, \& 
Amazeen, 2010; Hollenbeck, Ellis, Humphrey, Garza, \& Ilgen, 2011) and decision-making effectiveness (LePine, 2005; Randall, Resick, \& DeChurch, 2011; Resick, Murase, et al., 2010). In contrast, there has been less attention given to factors that may serve as antecedents of team adaptation. As such, we outline how self-efficacy beliefs (an input variable at the individual level), and mental models (a process variable at the team level) may be salient factors predicting the perceptions that referees have regarding team adaptation within the context of professional football and futsal.

\subsection{Self-efficacy beliefs and team adaptation perceptions}

In sport, in general, but in refereeing in particular, there is evidence of a positive, but variable relationship between self-efficacy and performance (Diotaiuti et al., 2017; Eskiyecek et al., 2019; Guillén et al., 2019; Laforge-MacKenzie \& Sullivan, 2014; Lirgg, Feltz, \& Merrie, 2016; Moritz et al., 2013). The model of Guillén and Feltz (2011) mention several self-efficacy outcomes, such as faster and more accurate decisions, lower stress levels or greater commitment to refereeing. Nevertheless, Lirgg et al. (2016) argue that self-efficacy affects behaviours in "terms of motivation (e.g., persistence, effort, choice of activities), emotions (e.g., arousal and anxiety), and cognitions (e.g., decision-making)" (p. 44), which, in turn, will influence actual performance outcomes. Further, they emphasise the need for more research in this field. Therefore, within the current study, at an individual-level, we investigate the cognitive factor of self-efficacy beliefs and examine its impact on team adaptation perceptions (Kozlowski et al., 2001; Maddux, 1995). The evidence that self-efficacy is an essential component of adaptation is provided by research within organisational settings (Kozlowski et al., 2001), which suggests that "adaptable behaviour is unlikely to occur unless one first has the confidence to perform such behaviour" (Griffin \& Hesketh, 2003, p. 67). It is known that self-efficacy enables individuals to adapt effectively to novel and changing situations (Callan, Terry, \& Schweitzer, 1994) and that measures of self-efficacy for adaptive behaviour were used to operationalise adaptability (Griffin \& Hesketh, 2003; Pulakos et al., 2002). Hence, authors have shown positive effects of self-efficacy on higher adaptive performance at individual and team levels of analysis (Griffin \& Hesketh, 2003; LePine, 2003; Pulakos et al., 2002).

Likewise, Burke et al. (2006) laid the foundation where individual factors may shape team adaptation. Maynard et al. (2015) echoed these sentiments when they theorised that individual-level factors are salient to consider in shaping team adaptation. Here, we built on this foundation and posited that referee teams need members to possess self-efficacy to adapt adequately in the face of complex and changing situations (Diotaiuti et al., 2017). Therefore, we contend that (Figure 1):

Hypothesis 1. Self-efficacy beliefs will predict perceptions of team adaptation.

\subsection{Mental models and team adaptation perceptions}

While Hypothesis 1 suggests that a team that is comprised of individuals with higher individual self-efficacy beliefs will result in enhanced levels of team adaptation perceptions, it begs the question of how team-level constructs may moderate such a relationship. Prior work has suggested that constructs such as mental models, experience and collective efficacy are salient for team adaptation (Maynard et al., 2015). Within the current study, our focus is on mental models because such cognitive structures are the basis for reasoning, decision-making and behaviour (Jones et al., 2011) and, therefore, experience and collective efficacy will be outside of the focus of this study.

Likewise, according to Cannon-Bowers et al. (1993), team mental models allow team members to anticipate other members' needs and actions and adapt their behaviours concerning the task demands and the other members. Similarly, from the organisational literature, there is

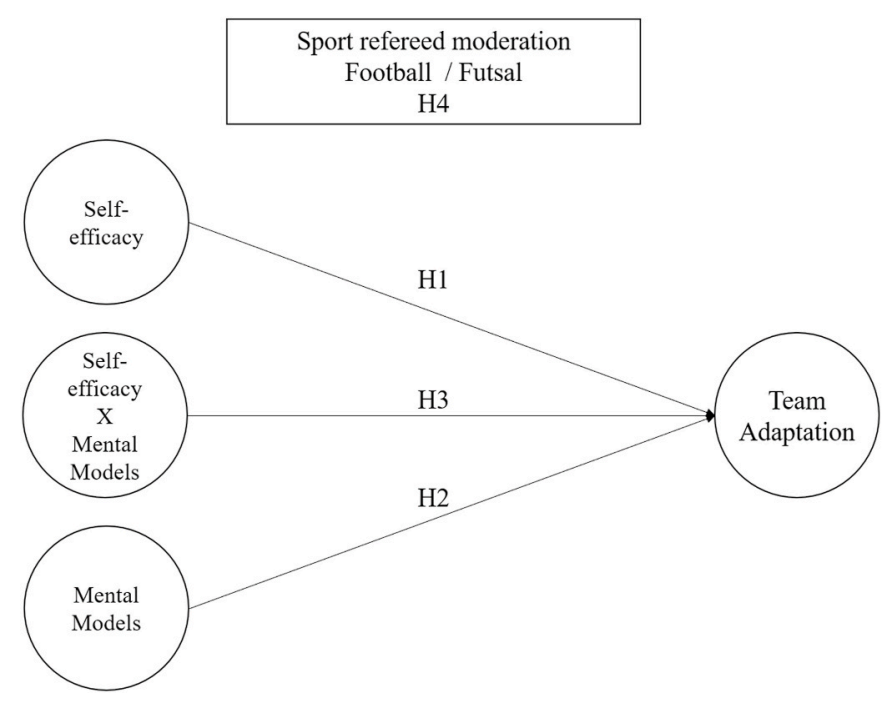

Figure 1. Research model and hypotheses.

evidence to suggest that mental models are essential to enhance team effectiveness through team processes such as coordination and communication (Marks et al., 2000; Mathieu, Heffner, Goodwin, Salas, \& Cannon-Bowers, 2000).

The context of football refereeing is an interesting one to examine team-level constructs because football referees rarely train with the exact team members who will perform during the game. Instead, even at the elite level, such interactions mainly occur in training events or technical seminars (Webb et al., 2016; Webb \& Thelwell, 2015). Therefore, it is difficult for refereeing teams to prepare for the game and coordinate tasks adequately (Boyer et al., 2015; Cunningham, Simmons, Mascarenhas, \& Redhead, 2014; Samuel, 2015), to develop a shared technical and tactical knowledge to be able to perform at the top-level (Hancock et al., 2018; Mallo et al., 2012; Mascarenhas et al., 2006; McEwan \& Beauchamp, 2014), to anticipate other members' needs and actions and adapt concerning the task demands and the other members (Cannon-Bowers et al., 1993; Hancock et al., 2018), or to learn continuously with experience and the team members (Collina, 2004; Cunningham et al., 2014; McEwan \& Beauchamp, 2014), among others that could improve shared mental models and, finally, performance. For instance, Boyer et al. (2015) enhanced the importance of good communication and coordination for football refereeing teams to perform better and suggested that mental models should be studied in the context of handball refereeing. Recently, Boyer et al. (2020) showed that assistant referees adjust their decision making according to the main referee decision' process. Finally, Mascarenhas, Collins, Mortimer, and Morris (2005) showed that shared mental model training improved the performance of rugby referees.

Unfortunately, little is known about the effects of team-level constructs within football refereeing research (Aragão e Pina et al., 2018; Slack, Maynard, Butt, \& Olusoga, 2013). Accordingly, even though it has yet to receive much research attention, we think it is essential to explore the moderating impact of mental models (see Filho \& Tenenbaum, 2012). As such, we expect that mental models will positively moderate the relationship between self-efficacy beliefs and perceptions of team adaptation. Namely, while self-efficacy should benefit the process of team adaption, this relationship should be even more pronounced when the team is on a similar page as the result of overlapping mental models. Therefore, in teams where individuals have overlapping cognitive structures (i.e., mental models), the salience of being confident as individuals (i.e., self-efficacy) should be even more salient for team adaptation perceptions (Marques-Quinteiro, Curral, Passos, \& Lewis, 2013; Santos, Passos, \& Uitdewilligen, 2016). Namely, having team members who have higher levels of self-efficacy and see the 
situation in a similar way (i.e., mental models) should be better able to adapt to changing circumstances (Hancock et al., 2018; Pulakos et al., 2002). Accordingly, we posit that (Figure 1):

Hypothesis 2. Mental models will predict perceptions of team adaptation.

Hypothesis 3. Mental models will moderate the relationship between self-efficacy beliefs and team adaptation perceptions such that as mental model agreement increases, the relationship between self-efficacy beliefs and team adaptation perceptions should be enhanced.

\subsection{Impact of football $v$ futsal contexts}

Ruled by Fédération Internationale de Football Association (FIFA), futsal, despite being a variant of football, is a different sport (Moore et al., 2014). The laws of the game are different; namely, the surface and size of the pitch, the size, weight and material of the ball, the width between the goalposts and height of the crossbar from the ground, the duration of the periods of play, the number of players and the number and the role of referees are different and, therefore, officiating a futsal game is different from officiating a football game (see Diotaiuti et al., 2017; Webb, 2016). In particular, while a football game "is controlled by a referee who has full authority to enforce the Laws of the Game" (Laws of the game $2017 / 18,2017$, p. 61 ), a futsal game "is controlled by two referees, the referee and the second referee, who have full authority to enforce the Futsal Laws of the Game" (Futsal Laws of the Game, 2015, p. 21). Therefore, football and futsal referees have different roles, tasks and responsibilities, operate in a different context, under several different circumstances, which may also require a different team mental model (see Boyer et al., 2020; Cannon-Bowers et al., 1993; Mohammed, Klimoski, \& Rentsch, 2000; Rouse, Cannon-Bowers, \& Salas, 1992). Hence, since self-efficacy is situation-specific (Bandura, 1977), it should be studied concerning the context of football and futsal refereeing.

Differences between futsal referees and football referees or assistant football referees were reported considering physical and physiological differences (Rebelo et al., 2011), the number of activities performed (Ahmed et al., 2017; Helsen \& Bultynck, 2004) and type of injuries (Moore et al., 2014). Considering only the sport of football, several researchers showed or suggested several differences among referees and assistant referees, such as separate training programmes (Helsen \& Bultynck, 2004), amount of decisions during the game (Catteeuw, Gilis, Jaspers, Wagemans, \& Helsen, 2010), physical demands during match-play (Mallo, Navarro, Aranda, \& Helsen, 2009; Weston, Drust, Atkinson, \& Gregson, 2011), the accuracy of decision-making (Mallo et al., 2012) and the decision-making process (Boyer et al., 2020).

Differences between referees of different sports have been reported regarding various variables such as burnout (Al-Haliq, Altahayneh, \& Oudat, 2014), perceptual judgements (Pizzera \& Raab, 2012) and decision-making (Mascarenhas, Collins, \& Mortimer, 2005a; 2005b). As such, in line with other researchers who have suggested that context needs to be taken into consideration in empirical research (e.g., Johns, 2006), and that referees' roles should be studied separately (Aragão e Pina et al., 2018; Diotaiuti et al., 2017), in the current study, we sought to understand if the differing contexts included in our study (i.e., football and futsal) would shape the relationships examined here (i.e., the relationships between self-efficacy beliefs, mental models, and perceptions of team adaptation). We suggest that these contexts are different enough to suggest that team dynamics may have differential impacts on referee team performance when comparing different sports (see Diotaiuti et al., 2017). That said; given the lack of research involving futsal referees (Ahmed et al., 2017; Moore et al., 2014), it is premature to hypothesise a specific difference between football and futsal referees. As such (Figure 1):

Hypothesis 4. We investigate whether there is a moderation effect of the sport refereed in the proposed model (sport refereed moderation).

\section{Methods}

\subsection{Participants}

In this study, out of 425 active football and futsal referees contacted for this study, 339 completed the questionnaires - an excellent response rate $(79.76 \%)$ when compared to other research projects within this context (e.g., Cuskelly \& Hoye, 2013; Perreau-Niel \& Erard, 2015; Praschinger, Pomikal, \& Stieger, 2011). Of the 339 surveys, one did not provide sex information; however, of those that did, our sample includes $90.18 \%$ men and $9.82 \%$ women who are part of the Portuguese Football Federation (Table 1). Likewise, these referees work at the national or professional level and have experience levels that range from 1 season to 27 seasons $(M=12.81, S D=5.24)$.

\subsection{Procedures}

The Institutional Review Board and the National Referees' Committee approved this study. Electronic informed consent was obtained from all participants, and confidentiality for their responses was assured. Data was collected at two different time points to reinforce causality inferences (Mathieu \& Taylor, 2006) and to reduce common-method variance (Brannick, Chan, Conway, Lance, \& Spector, 2010). The first online questionnaire was sent in April 2016, toward the end of the season, to allow participants to consider the full season. The second questionnaire was also addressed by email, in May 2016 (i.e., one month after the first questionnaire). Of note is the fact that the second questionnaire occurred before the publication of the season overall referees' performance, to allow participants to evaluate their experiences in their teams during the season, independently of "objective" scores, which could bias their perceptions. Self-efficacy beliefs and team mental models were measured in the first questionnaire, while perceptions of team adaptation were included in the second questionnaire.

\subsection{Measures}

\subsubsection{Self-efficacy beliefs}

Self-efficacy was measured with five items adapted from the General Self-Efficacy Scale (Nunes, Schwarzer, \& Jerusalem, 1999). Example items are "I have the necessary skills to perform well as a referee/assistant referee." and "I do not have any problems adjusting to the different refereeing teams." ( $1=$ "Totally disagree" to $7=$ "Totally agree").

\subsubsection{Mental models}

In other studies, mental models were measured with a variety of techniques, such as Pathfinder, multi-dimensional scaling, interactively elicited cognitive mapping, or text-based cognitive mapping, which encompasses both elicitation, i.e., "to determine the components or

Table 1

Participants' sociodemographic characteristics per sport refereed.

\begin{tabular}{|c|c|c|c|}
\hline & \multicolumn{2}{|l|}{ Football } & \multirow{2}{*}{$\begin{array}{l}\text { Futsal } \\
(n=135)\end{array}$} \\
\hline & $\begin{array}{l}\text { Referee } \\
(n=160)\end{array}$ & $\begin{array}{l}\text { Assistant } \\
(n=33)\end{array}$ & \\
\hline Sex (male) $\%$ & $81.8 \%$ & $100.0 \%$ & $97.0 \%$ \\
\hline Working years as referee $M(S D)$ & $12.43(5.06)$ & $18.61(4.23)$ & 11.84 (4.79) \\
\hline \multicolumn{4}{|l|}{ Academic level } \\
\hline High School 9th grade & $3.8 \%$ & $12.1 \%$ & $6.8 \%$ \\
\hline High School 12th grade & $35.4 \%$ & $51.5 \%$ & $53.4 \%$ \\
\hline Graduation & $36.7 \%$ & $30.3 \%$ & $29.3 \%$ \\
\hline Post-graduation & $24.1 \%$ & $6.1 \%$ & $10.5 \%$ \\
\hline
\end{tabular}

Note. Some referees $(n=11)$ did not indicate the sport refereed. 
content of a mental model", and representation, i.e., "to reveal the structure of data or determine the relationships between elements in an individual's mind", techniques (Mohammed et al., 2000, p. 129). Considering the goal of this preliminary study on the context of football and futsal refereeing, the sample we wanted to access, i.e., the population of the Federation referees, and the fact that we anticipated having only limited access to the sample, we opted to use self-report instruments, as many other authors do (e.g., Blickensderfer, Cannon-Bowers, \& Salas, 1997; Santos, Uitdewilligen, \& Passos, 2015), since we wanted to assess the degree of sharedness between team members on items addressing the various forms of teamwork functioning. As such, we consciously decided not to focus on measuring the underlying organisational structure of an individual's or team's knowledge domain (Mohammed et al., 2000). Therefore, in the current study, we followed a precedent set by prior researchers (e.g., Santos et al., 2015) and developed a measure of mental models (Resick, Dickson, Mitchelson, Allison, \& Clark, 2010).

Specifically, we created 13 items to operationalise the mental models, based on the four types of models proposed by Cannon-Bowers et al. (1993). During a dynamic and complex context such as refereeing a game, multiple mental representations are required, and refereeing teams need, among other, to understand how to best use the audio communication system, the electronic flags and the VAR (equipment model), to understand the context when applying the laws of the game (task model), to understand the roles and responsibilities of each team member and how to interact to each other (team interaction model) and to understand the teammate's knowledge, skills, abilities, preferences and tendencies (team model). As such, we are following best practices in mental model measurement considering multiple dimensions of mental models. Hence, we asked three refereeing experts, i.e., international referees with vast experience, to adapt the items to the specific context of football refereeing (Marks et al., 2000). We discussed each item with the three experts and established a consensus version of the 13 items. This scale was administered in survey 1 with example items including: "On my team, members have a similar understanding of the features that are needed to make decisions during a game." and "On my team, members have a similar understanding of the technology and tools needed to make decisions during a game" ( 1 = "Totally disagree" to $7=$ “Totally agree").

\subsubsection{Team adaptive perceptions}

Team adaptive perceptions were measured in survey 2 with the Team Adaptive Performance Scale, adapted from Marques-Quinteiro et al. (2015). Example items were "My team was effective using creative ideas to overcome the problems that have arisen." and "My team was effective in finding innovative ways to deal with unexpected situations." ( $1=$ "Totally disagree" to 7 = "Totally agree").

\subsubsection{Type of sport}

Given that our research question seeks to assess the impact that type of sport refereed (i.e. football vs futsal) had on the relationships examined here, we coded the type of sport that each referee was engaged with.

\subsection{Data analysis}

All the analysis were performed within $R$ (R Core Team, 2019) using the integrated development environment, RStudio (RStudio Team, 2019). The descriptive statistics were obtained with the skimr package (McNamara, Arino de la Rubia, Zhu, Ellis, \& Quinn, 2018). The coefficient of variation (CV) was calculated through the package sjstats (Lïdecke, 2019), the standard error of the mean (SEM) was estimated by the plotrix package (Lemon, 2006), and the mode was calculated with the package DescTools (Signorell et al., 2019). Severe univariate normality violations were considered for absolute values of $\mid$ sk $\mid>3$ and $|\mathrm{ku}|>7$ (Finney \& DiStefano, 2013). To assess the validity evidence based on the internal structure, the dimensionality and reliability of the measurement models were evaluated. Particularly, the dimensionality was evaluated with exploratory factor analysis (EFA) or confirmatory factor analysis (CFA) depending on whether the instruments had or not a known dimensionality.

Regarding the EFA, the Kaiser-Meyer-Olkin (KMO) coefficient was used as a measure of sampling adequacy (Kaiser \& Rice, 1974). The Bartlett's test (Bartlett, 1951) was chosen to test if the correlation matrix was factorable (i.e., the correlations differ from 0) (Revelle, 2019). KMO values $>0.8$ and Bartlett's test significance $\leq 0.05$, indicating adequate sampling (Marôco, 2018). The number of factors was determined through the comparison data (CD) approach, as suggested by Ruscio and Roche (2012), which stated that this technique outperforms Parallel Analysis. CD is a variant of Parallel Analysis that reproduces the correlation matrix rather than generating random data (Courtney, 2012). The extraction of the factors was performed using the principal components analysis with weighted least squares factoring method and using the $\rho_{P C}$ matrix. The oblimin transformation rotation was used. The cut-off for items' loadings was 0.40 . The $\mathrm{CD}$ analysis was conducted using the package RGenData (Ruscio, 2018). The Bartlett's test, the KMO coefficient, factors' extraction and the $\rho_{P C}$ were produced using the package psych (Revelle, 2019).

The CFAs were conducted with the lavaan package (Rosseel, 2012) using the maximum likelihood estimation with robust (Huber- White) standard errors (Finney, DiStefano, \& Kopp, 2016). As goodness-of-fit indices, we used the TLI (Tucker Lewis Index), NFI (Normed Fit Index), $\chi^{2} / \mathrm{df}$ (ratio chi-square and degrees of freedom), CFI (comparative fit index), the RMSEA (root mean square error of approximation), and the SRMR (Standardised Root Mean Square Residual). Since the new instrument's items were considered as categorical variables, the scaled variants of the goodness-of-fit indices were reported. For values of $\chi^{2 /} d f$ $<5$, values of CFI, NFI and TLI $>0.95$, values of SRMR $<0.08$, and RMSEA $<0.08$ the fit of the model was considered good (Boomsma, 2000; Byrne, 2010; Hoyle, 1995; McDonald \& Ho, 2002). Possible model modifications were weighted based on a theoretical basis and the modification indices ( $>50 ; p<0.001$ ). The reliability of the scores was assessed with estimates of internal consistency $\omega$ (Raykov, 2001); using the package semTools (Jorgensen, Pornprasertmanit, Schoemann, \& Rosseel, 2019) for the CFAs and the userfriendlyscience package (Peters, 2018), where higher values were indicative of better internal consistency results.

The structural model was tested through structural equation modeling using the lavaan package (Rosseel, 2012), where a two-step approach was used (Marôco, 2014). The structural model through structural equation modelling using the lavaan package. The latent moderation variable was produced using the semTools package (Jorgensen et al., 2019) using match-paired approach (Marsh, Wen, \& Hau, 2004) and double-mean centring for the product of the indicators (Lin, Wen, Marsh, \& Lin, 2010). When testing the moderation effects of variables that are not directly observed, the measurement error should be accounted, as such, latent variable moderation should be preferred (Cortina, Markell-Goldstein, Green, \& Chang, 2019; Sarstedt, Hair, Nitzl, Ringle, \& Howard, 2020). The idea that measurement error can be ignored consists of what Edwards (2009) classified as one "of the seven deadly myths of testing moderation" (p. 143). The multiple group comparisons were assessed using the Wald test (Buse, 1982) within the lavaan package (Rosseel, 2012). The moderation effect (i.e., sport refereed) was significant in each specific path considering an $\alpha=0.05$.

\section{Results}

The results showed that all the paths tested in the first model were statistically significant, namely the path from self-efficacy to team adaptation ( $\left.\mathrm{H} 1 ; \beta_{S E}=0.150, p=0.049\right)$, the path from mental models to team adaptation ( $\left.\mathrm{H} 2 ; \beta_{M M}=0.586 ; p<0.001\right)$, and the path from the interaction factor to team adaptation (H3; $\left.\beta_{\text {SExMM }}=0.136, p=0.010\right)$. 
The sports refereed moderation (H4) showed that the path from mental models to team adaptation $\left(\Delta \chi^{2}=4.150, \Delta d f=1, p=0.042, \beta_{f u t s a l}=\right.$ $0.714, \beta_{\text {football }}=0.225$ ) and the path from the interaction factor to team adaptation $\left(\Delta \chi^{2}=3.934, \Delta d f=1, p=0.047, \beta_{\text {futsal }}=0.221, \beta_{\text {football }}=\right.$ $-0.064)$ presented statistically significant differences between the two sports.

\subsection{Measurement model}

\subsubsection{Items' distributional properties}

The items' descriptive statistics are presented in Table 2. The items of the Team Adaptive Performance Scale presented acceptable evidence in terms of psychometric sensitivity, without severe univariate normality violations. However, none of the items received the full range of possible answers (i.e., 1 to 7). The General Self-Efficacy Scale measure's items each had acceptable distributional properties, except for item 5 with $|\mathrm{ku}|>7\left(\mathrm{ku}_{\text {Item } 5}=8.19\right)$ which represents a severe violation to the univariate normality (Finney \& DiStefano, 2013). Additionally, none of the items presented the full range of possible answers (i.e., 1 to 7). The referee mental model measure only presented one item with severe univariate normality $\left(\mathrm{ku}_{\text {item }} 13=7.69\right)$, while all the other items revealed acceptable psychometric sensitivity. Four of the items did not present the full range of possible answers (i.e., 1 to 7).

\subsubsection{Dimensionality}

The Team Adaptive Performance Scale CFA revealed a good fit to the data $\left(\chi^{2}(8)=29.051, p<0.001, n=304, \chi^{2} / d f=3.631, N F I=0.976\right.$, $C F I=0.982, T L I=0.967, S R M R=0.025, R M S E A=0.093, P($ rmsea $\leq$ $0.05)=0.023,90 \% \mathrm{CI}] 0.058 ; 0.131$ [). In this model, team adaptation was assumed as a second-order latent factor (i.e., team adaptation) with two first-order factors. Since with two first-order factors, there are insufficient degrees of freedom to fit the model, the structural weights $(\gamma)$ were constrained to be equal. The minimum factor loading was high $\left(\lambda_{i} \geq 0.75\right)$ as the structural weigh were also high $\left(\gamma_{i} \geq 0.94\right)$. The AVE was high for both first-order factors $\left(\mathrm{AVE}_{F 1}=0.66, \mathrm{AVE}_{F 2}=0.71\right)$. Since the mental model measures should be adapted to each context (e.g.,
Smith-Jentsch, Cannon-Bowers, Tannenbaum, \& Salas, 2008), an EFA was conducted. The mental model measure met the Kaiser-Meyer-Olkin coefficient (0.947) and Bartlett's test of sphericity $\left(\chi^{2}(78)=3572.941\right.$; $p<0.001$ ). The comparison data suggested that the best solution contains a one-factor model. The one-factor solution was adopted, and the results of the correspondent EFA revealed $60.0 \%$ of explained variance, with satisfactory minimum factor loading $\left(\lambda_{i} \geq 0.72\right)$.

The self-efficacy single-factor model revealed an unsatisfactory fit to the data $\left(\chi^{2}(5)=63.751, p<0.001, n=314, \chi^{2} / d f=12.750, N F I=\right.$ $0.846, C F I=0.855, T L I=0.710, S R M R=0.068, R M S E A=0.193, P$ (rmsea $\leq 0.05)<0.001,90 \%$ CI ]0.153; 0.237[). The modification indices were inspected. One correlation between the residuals of item 4 and item 5 residuals was added $(r=0.458, p=0.004)$. Such modification seems acceptable since both items belong to the same factor (Kline, 2016). This modification improved the goodness-of-fit indices, changing the model fit to be good $\left(\chi^{2}(4)=5.648, p=0.227, n=314, \chi^{2} / d f=\right.$ 1.412, NFI $=0.986, C F I=0.996, T L I=0.990, S R M R=0.027, R M S E A=$ $0.036, P(r m s e a \leq 0.05)=0.559,90 \%$ CI ]0.000; 0.099[). Furthermore, the minimum factor loading was nearly satisfactory $\left(\lambda_{i} \geq 0.41\right)$ the AVE was low $\left(\mathrm{AVE}_{S E}=0.31\right)$.

The latent variable representing the moderation between self-efficacy's and mental models' measures was created using three indicators from each measure (i.e., the highest loading, the medium and the lowest; in order to capture the different facets of each construct). This solution was adopted since the instruments have different number of items. One variance was fixed to 0.001 in order to avoid negative variance, which released one degree of freedom, passing from a saturated model to an overidentified model. The goodness-of-fit indices presented a perfect fit $\left(\chi^{2}(1)=0.860, p=0.354, n=314, \chi^{2} / d f=0.860, N F I=0.997, C F I=\right.$ $1.000, T L I=1.000, S R M R=0.013, R M S E A=0.000, P(r m s e a \leq 0.05)=$ $0.519,90 \%$ CI ] 0.000 ; 0.145 [) with an acceptable minimum factor loading $\left(\lambda_{i} \geq 0.46\right)$ and a nearly acceptable AVE $\left(\operatorname{AVE}_{S E}=0.43\right)$.

\subsubsection{Reliability of the scores}

The second-order latent variable internal consistency estimates of the team adaptation perceptions, the evidence was good $\left(\omega_{L 1}=0.87\right.$;

Table 2

Items' distributional properties $(\mathrm{N}=339)$.

\begin{tabular}{|c|c|c|c|c|c|c|c|c|c|c|c|c|}
\hline Item & $M$ & $S D$ & Min & $M d n$ & $\operatorname{Max}$ & Histogram & Mode & SEM & $C V$ & Sk & $\mathrm{Ku}$ & $\%$ missing \\
\hline \multicolumn{13}{|c|}{ Team Adaptive Performance Scale } \\
\hline Item 1 & 4.70 & 0.84 & 2 & 5 & 6 & & 5.00 & 0.05 & 0.18 & -0.84 & 1.35 & 10.32 \\
\hline Item 2 & 4.74 & 0.85 & 1 & 5 & 6 & & 5.00 & 0.05 & 0.18 & -1.09 & 2.15 & 10.32 \\
\hline Item 3 & 4.70 & 0.90 & 1 & 5 & 6 & & 5.00 & 0.05 & 0.19 & -0.91 & 1.48 & 10.32 \\
\hline Item 4 & 4.99 & 0.77 & 2 & 5 & 6 & & 5.00 & 0.04 & 0.15 & -0.90 & 2.15 & 10.32 \\
\hline Item 5 & 4.83 & 0.77 & 1 & 5 & 6 & & 5.00 & 0.04 & 0.16 & -1.05 & 3.08 & 10.32 \\
\hline Item 6 & 4.81 & 0.79 & 1 & 5 & 6 & & 5.00 & 0.05 & 0.16 & -0.92 & 2.26 & 10.32 \\
\hline Item 7 & 4.88 & 0.89 & 2 & 5 & 6 & & 5.00 & 0.05 & 0.18 & -0.94 & 1.44 & 10.32 \\
\hline Item 8 & 4.93 & 0.77 & 2 & 5 & 6 & & 5.00 & 0.04 & 0.16 & -0.74 & 1.27 & 10.32 \\
\hline \multicolumn{13}{|c|}{ General Self-Efficacy Scale } \\
\hline Item 1 & 6.37 & 0.69 & 3 & 6 & 7 & & 6.00 & 0.04 & 0.11 & -1.21 & 2.96 & 7.37 \\
\hline Item 2 & 5.83 & 1.10 & 2 & 6 & 7 & & 6.00 & 0.06 & 0.19 & -1.20 & 1.70 & 7.37 \\
\hline Item 3 & 6.47 & 0.61 & 3 & 7 & 7 & & 7.00 & 0.03 & 0.09 & -1.04 & 2.14 & 7.37 \\
\hline Item 4 & 6.28 & 0.84 & 2 & 6 & 7 & & 7.00 & 0.05 & 0.13 & -1.66 & 4.22 & 7.37 \\
\hline Item 5 & 6.48 & 0.72 & 2 & 7 & 7 & & 7.00 & 0.04 & 0.11 & -2.14 & 8.19 & 7.37 \\
\hline \multicolumn{13}{|c|}{ Mental Models } \\
\hline Item 1 & 6.04 & 0.87 & 2 & 6 & 7 & & 6.00 & 0.05 & 0.14 & -1.36 & 3.10 & 7.37 \\
\hline Item 2 & 6.04 & 0.89 & 2 & 6 & 7 & & 6.00 & 0.05 & 0.15 & -1.47 & 3.87 & 7.37 \\
\hline Item 3 & 6.11 & 0.84 & 2 & 6 & 7 & & 6.00 & 0.05 & 0.14 & -1.64 & 4.96 & 7.37 \\
\hline Item 4 & 5.94 & 0.85 & 3 & 6 & 7 & & 6.00 & 0.05 & 0.14 & -1.01 & 1.69 & 7.37 \\
\hline Item 5 & 5.81 & 1.16 & 1 & 6 & 7 & & 6.00 & 0.07 & 0.20 & -1.60 & 3.34 & 7.37 \\
\hline Item 6 & 6.07 & 0.91 & 1 & 6 & 7 & & 6.00 & 0.05 & 0.15 & -1.61 & 4.78 & 7.37 \\
\hline Item 7 & 6.10 & 0.94 & 1 & 6 & 7 & & 6.00 & 0.05 & 0.15 & -1.77 & 5.18 & 7.37 \\
\hline Item 8 & 6.02 & 0.97 & 1 & 6 & 7 & & 6.00 & 0.05 & 0.16 & -1.66 & 4.60 & 7.37 \\
\hline Item 9 & 6.07 & 0.93 & 1 & 6 & 7 & & 6.00 & 0.05 & 0.15 & -1.76 & 5.03 & 7.37 \\
\hline Item 10 & 5.98 & 0.92 & 1 & 6 & 7 & & 6.00 & 0.05 & 0.15 & -1.49 & 4.07 & 7.37 \\
\hline Item 11 & 6.03 & 0.89 & 1 & 6 & 7 & & 6.00 & 0.05 & 0.15 & -1.73 & 5.89 & 7.37 \\
\hline Item 12 & 6.00 & 0.90 & 1 & 6 & 7 & & 6.00 & 0.05 & 0.15 & -1.70 & 5.42 & 7.37 \\
\hline Item 13 & 6.17 & 0.89 & 1 & 6 & 7 & & 6.00 & 0.05 & 0.14 & -1.99 & 7.69 & 7.37 \\
\hline
\end{tabular}


$\left.\omega_{L 2}=0.96 ; \omega_{\text {partial } L 1}=0.92\right)$. The mental model measures the estimate of internal consistency revealed a satisfactory value $(\omega=0.95)$. The selfefficacy measure revealed a marginally acceptable internal consistency value $(\omega=0.65)$. The latent moderation measure presented an acceptable internal consistency value $(\omega=0.69)$.

\subsection{Structural model}

The structural model presented an acceptable fit to the data $\left(\chi^{2}(316)\right.$ $=707.780, p<0.001, \chi^{2} / d f=2.240, n=279, N F I=0.859, C F I=0.916$, $T L I=0.907, S R M R=0.048, R M S E A=0.067, P($ rmsea $\leq 0.05)<0.001$, $90 \%$ CI ]0.060; 0.073[). All the regression paths were statistically significant, namely self-efficacy $\left(\mathrm{H} 1 ; \beta_{S E}=0.150 ; p=0.049\right)$; mental models $\left(\mathrm{H} 2 ; \beta_{M M}=0.586 ; p<0.001\right)$; and the moderation between mental models and self-efficacy $\left(\mathrm{H} 3 ; \beta_{S E x M M}=0.136 ; p=0.010\right)$. Finch and French (2015) stated that the standardized coefficient for the interaction term should be corrected, as so, the corrected coefficient in smaller than the uncorrected one $\left(\beta_{S E x M M}\right.$ corrected $\left.=0.058\right)$. The model explained $46.1 \%$ of the team adaptation variance $\left(r_{\text {team adaptation }}^{2}=\right.$ $0.461)$. Regarding the latent continuous moderation, the effect was not significant ( $p=0.285$ ) when the mental models were low (1 SD below). Table 3 shows the standardized factor weights $(\beta)$ and their $95 \%$ confidence intervals.

The multigroup full structural equation model revealed a marginally acceptable fit $\left(\chi^{2}(633)=1248.081, p<0.001, \chi^{2} / d f=1.972, n_{\text {futsal }}=\right.$ $119, n_{\text {football }}=135, N F I=0.758, C F I=0.862, T L I=0.847, S R M R=$ 0.067, RMSEA $=0.087, P($ rmsea $\leq 0.05)<0.001,90 \%$ CI ] 0.080; 0.095 [). Table 4 shows the corresponding $\beta$ s for the football referees and for the futsal referees with their correspondent $95 \%$ confidence intervals.

The comparison between the paths among the sport refereed presented two statistically significant differences (H4). The corrected interaction coefficient was calculated both for futsal $\left(\beta_{\text {SExMM }}\right.$ corrected $=$ $0.101)$ and for football referees $\left(\beta_{\text {SExMM }}\right.$ corrected $\left.=-0.028\right)$. The path from self-efficacy to team adaptation perceptions did not present statistically significant differences $\left(\Delta \chi^{2}=0.992, \Delta d f=1, p=0.319\right)$. The path from mental models to team adaptation perceptions had a statistically significant difference between sport refereed $\left(\Delta \chi^{2}=4.150\right.$, $\Delta d f=1, p=0.042)$, with the football referees' path being lower $\left(\beta_{\text {football }}\right.$ $=0.225)$ than the path of futsal referees $\left(\beta_{\text {futsal }}=0.714\right)$. Finally, the path from the moderation MMxSE to team adaptation had statistically significant differences $\left(\Delta \chi^{2}=3.934, \Delta d f=1, p=0.047\right)$, with the path of futsal referees being higher $\left(\beta_{f u t s a l}=0.221\right)$ than the path of football referees $\left(\beta_{\text {football }}=-0.064\right)$.

\section{Discussion}

Football and futsal refereeing are highly demanding sports that take place within dynamic contexts. Under these circumstances, beliefs of self-efficacy (an individual-level cognitive factor) are essential to reduce stress, and enhance confidence and performance (Myers et al., 2012; Nazarudin et al., 2014). Hence, it is known from organisational literature that this kind of context requires team adaptation to improve performance and, therefore, teams must possess shared mental models (Maynard et al., 2015). Nevertheless, competencies and responsibilities which have primarily only been considered at the main referee level, should (we argue) also contemplate the entire refereeing team. In particular, we contend that training should consider the team's characteristics because, usually, the whole refereeing team does not train together, but also the team' composition, since it may depend on the type of the game and the competition they are assigned to, i.e., national leagues, national cups or international games (see Aragão e Pina et al., 2018; Plessner \& MacMahon, 2013).

Interestingly, even though referees work in teams and the importance of teams within the sports of football and futsal are increasing, the underlying literature on refereeing in these sports lacks attention on the refereeing team. Therefore, this study is a first step in trying to understand how individual factors contribute to team adaptation - an essential predictor in referee team performance. Specifically, in this study, we investigated how an individual-level cognitive factor (self-efficacy beliefs) influenced team adaptation perceptions and how this relationship is shaped by a team-level cognitive factor (mental models) within the football and futsal refereeing context.

Empirically, it is easy to envision several situations where refereeing teams may need to adapt in order to have excellent performance, such as weather, culture, type and moment of the competition, club's rivalry, broadcasting, the number of spectators, stadium type, game pace, score progress, kind of players, coaches and refereeing team composition (McEwan \& Beauchamp, 2014; Unkelbach \& Memmert, 2008). As such, it is crucial to understand how referee teams get to the point where they can adapt (see Boyer et al., 2020). Until now, such investigations have been non-existent within the domain of football/futsal refereeing. This study addresses this gap by examining the relationship between self-efficacy beliefs and mental models in creating perceptions of team adaptation within football and futsal referees.

We found support for our hypothesised positive relationship between self-efficacy beliefs and team adaptation perceptions, which we hope will trigger the attention of researchers to explore this topic further (Guillén \& Feltz, 2011). Hence, refereeing organisations should include self-efficacy in refereeing training programmes to improve team adaptation, as supported by the results of this study. Our results suggest that it is important to enhance referees' self-efficacy for adaptation (Nizam et al., 2014). However, such efficacy is also likely to have a positive impact on satisfaction (Diotaiuti et al., 2017) and prevent the negative effect on attention, reaction times, judgments and stress that a lack of self-efficacy may cause (Guillén \& Feltz, 2011). As such, in addition to the fact that our results may suggest the need for self-efficacy training and interventions (Lirgg et al., 2016), the current study may also indicate that self-efficacy should be a factor considered when constructing referee teams within the sports of football and futsal.

Hypothesis 2 was also successfully tested, with all paths presenting statistically significant coefficients. The path with the highest effect size was the shared mental model path to team adaptation, which highlights the role of such a construct in these kinds of teams (Filho \& Tenenbaum, 2012). Interestingly, the moderation between mental models and self-efficacy was not statistically significant when the mental models were low, showing that the self-efficacy beliefs' impact on the team adaptation might need medium to high levels of mental models. This fact is an indicator of the importance of mental models to enhance individual beliefs in benefit of the team. In other words, the relationship between self-efficacy and team adaptation is influenced by an individual's perceptions of the team's mental models.

Nevertheless, as mentioned before, mental models research on

Table 3

Structural model paths (dependent variable: team adaptation).

\begin{tabular}{|c|c|c|c|c|c|c|}
\hline Indicator & $B$ & $S E$ & $Z$ & ] 95\% CI [ & $\beta$ & $p$-value \\
\hline Self-Efficacy & 0.209 & 0.106 & 1.967 & $0.001 ; 0.417$ & 0.150 & 0.049 \\
\hline Mental Models & 0.630 & 0.097 & 6.507 & $0.440 ; 0.819$ & 0.586 & $<0.001$ \\
\hline MM x SE & 0.126 & 0.049 & 2.584 & $0.030 ; 0.222$ & 0.136 & 0.010 \\
\hline Moderation: - 1SD MM & 0.128 & 0.119 & 1.070 & $-0.106 ; 0.361$ & 0.014 & 0.285 \\
\hline Moderation: + 1SD MM & 0.290 & 0.105 & 2.772 & $0.085 ; 0.495$ & 0.285 & 0.006 \\
\hline
\end{tabular}


Table 4

Futsal and football referees' structural model (dependent variable: team adaptation).

\begin{tabular}{|c|c|c|c|c|c|c|c|}
\hline Indicator & $B$ & $S E$ & $Z$ & ] 95\% CI [ & $\beta$ & $p$-value & Sport refereed \\
\hline Self-Efficacy & 0.258 & 0.154 & 1.674 & $-0.044 ; 0.559$ & 0.169 & 0.094 & Futsal \\
\hline Mental Models & 0.738 & 0.123 & 5.997 & $0.496 ; 0.979$ & 0.714 & $<0.001$ & Futsal \\
\hline MM x SE & 0.193 & 0.053 & 3.618 & $0.088 ; 0.297$ & 0.221 & $<0.001$ & Futsal \\
\hline Moderation: - 1SD MM & 0.103 & 0.154 & 0.673 & $-0.198 ; 0.405$ & -0.053 & 0.501 & Futsal \\
\hline Moderation: + 1SD MM & 0.412 & 0.172 & 2.394 & $0.075 ; 0.748$ & 0.390 & 0.017 & Futsal \\
\hline Self-Efficacy & 0.519 & 0.213 & 2.438 & $0.102 ; 0.937$ & 0.357 & 0.015 & Football \\
\hline Mental Models & 0.322 & 0.162 & 1.986 & $0.004 ; 0.640$ & 0.225 & 0.047 & Football \\
\hline MM x SE & -0.075 & 0.124 & -0.603 & $-0.317 ; 0.168$ & -0.064 & 0.547 & Football \\
\hline Moderation: - 1SD MM & 0.554 & 0.249 & 2.227 & $0.066 ; 1.041$ & 0.421 & 0.026 & Football \\
\hline Moderation: + 1SD MM & 0.485 & 0.188 & 2.576 & $0.116 ; 0.854$ & 0.294 & 0.010 & Football \\
\hline
\end{tabular}

football and futsal refereeing is scarce, which may explain why mental models are not systematically, deliberately and explicitly included on refereeing training programs (Mascarenhas et al., 2005). However, the results may indicate that referees are learning by themselves, which takes more time and effort to have practical effects. Considering football and futsal dynamics and unpredictability, we think it is crucial to provide training on mental models to help referees to coordinate, communicate and decide better and, after all, to improve match performance levels (Cannon-Bowers et al., 1993; Mallo et al., 2012; Mascarenhas et al., 2006; McEwan \& Beauchamp, 2014).

We investigated whether there is a moderation effect of the sport refereed in the proposed model (H4), and results show that both the path from the moderation MMxSE to team adaptation and the path from mental models to team adaptation had statistically significant differences, with the path of futsal referees being higher than the path of football referees in both cases, which means that futsal and football referees perceived the tested model differently. While futsal is a variant sport of football, the context where it takes place (McEwan \& Beauchamp, 2014) and the related constraints (see Araújo \& Davids, 2016) contributes to the uniqueness of futsal as a sport and, therefore, to the futsal refereeing uniqueness. Within football, there is one referee that leads the entire team; however, in futsal, there is a team of two referees who have in essence the same responsibilities. Consequently, the futsal refereeing team process is different from the refereeing team football process. That said, we hope that these results contribute to an expansion of researchers interested in this field and to raise the awareness of refereeing government bodies to the uniqueness of futsal refereeing. Such a contribution can serve as a warning for researchers who feel tempted to join referees' samples of different sports, such as football and futsal, due to the potential small sample size (Aragão e Pina et al., 2018).

Finally, our findings further demonstrate the need for more research on team phenomenon within the context of football and futsal refereeing as we found evidence that as mental model agreement increases, the relationship between self-efficacy beliefs and team adaptation perceptions is enhanced. Considering this result, not only do practitioners and academics need to more fully examine individual-level factors that may shape team adaptation within this context but also salient team-level factors. Research has highlighted the importance of mental models for reasoning, decision-making and behaviour (Jones et al., 2011) and has examined mental model's role in enhancing team effectiveness (Marks et al., 2000; Mathieu et al., 2000). Therefore, mental models must be given more attention within the refereeing governing bodies (e.g., providing mental models training programs for football and futsal referees).

\section{Limitations and future directions}

While we feel that the current study has several strengths such as an interesting sample, excellent response rate, and multiple periods over which data was collected; we cannot ignore the fact that this study has its limitations and here we mention two of them. First, the current study's data was collected using self-report techniques. We have used adaptations of existing measures specifically for the referee's context (Mohammed et al., 2000; Pulakos et al., 2002), although we assessed the validity of evidence of such measures, as recommended by best practices (Heggestad et al., 2019). As such, future research may want to build upon the work developed here and create other means by which to measure team adaptation given that team mental models and self-efficacy are most appropriately assessed by the individual members of the referee teams. For instance, it may be possible for future researchers to watch videos of game footage and evaluate the extent to which referee teams had to adapt during a given game.

Likewise, in the current study, our emphasis was on factors that influence team adaptation, given the lack of research that has considered the antecedents of team adaptation. However, future researchers may find it valuable to build upon our work and consider not only the constructs that we contemplated here but also other individual-level factors (e.g., cognitive ability, personality factors, past experiences) or teamlevel factors (e.g., experience and collective efficacy) (Maynard et al., 2015). For instance, future research could try to connect team adaptation perceptions to actual game performance data as assessed by independent evaluators. By doing so, future research could also extend our work as such independent evaluation of team performance (and possibly team adaptation) can reduce the concern of self-report data which is a limitation of the current study.

While we are pleased with the amount of data that we were able to obtain from a unique population - professional sports referees, our data were obtained from individual referees; thus, we could not connect the responses to particular teams of referees. Therefore, rather than being able to connect our data to individual teams, we have individual-level perceptions about all the teams that each referee worked with across the entire football season. So, while our study is valuable as it opens the door for future research on team dynamics within this exciting context, hopefully, future research will build upon our work in a way that overcomes this limitation. Namely, future research could extend our work here by examining a complete referee team and investigating how they perform within a single game to understand better the factors that shape team dynamics and performance. Additionally, future research should also consider similar sample sizes of the football and futsal referees' samples. Despite such concern, the present study included almost $80 \%$ of the active national football and futsal referees in the context examined.

While we acknowledge these limitations and we hope that future research can address them with additional studies in this area, we hope that our work here can be viewed as a helpful first step to the conversation centred on team phenomenon within the context of football and futsal refereeing.

\section{Conclusion}

Given their popularity around the globe, the sports of football and futsal are a connecting point across numerous cultures. In part because of this almost universal appeal, the sport of football and futsal are big business. As their cultural and economic importance has grown, there has 
been increased attention to the critical role that referees play within these sports. As such, research has increasingly examined factors that shape the performance of their referees. However, much of this work seems to ignore the fact that referees work in teams and therefore it is not enough only to consider individual-level referee performance, but research should also consider referee team dynamics and performance. Unfortunately, this has not been the case to date. As such, the current study offers what we hope is a starting point for research on football and futsal refereeing as it sets the stage for more work to examine team-level constructs within these contexts, given the salience of teamwork within these sports' refereeing.

\section{CRediT authorship contribution statement}

João Aragão e Pina: Conceptualization, Methodology, Software, Validation, Formal analysis, Investigation, Resources, Data curation, Writing - original draft, Writing - review \& editing, Visualization, Supervision, Project administration. Ana Margarida Passos: Conceptualization, Methodology, Software, Validation, Formal analysis, Writing original draft, Writing - review \& editing, Supervision. M. Travis Maynard: Conceptualization, Methodology, Validation, Writing - original draft, Writing - review \& editing. Jorge Sinval: Conceptualization, Methodology, Software, Validation, Formal analysis, Resources, Data curation, Writing - review \& editing, Visualization.

\section{Declaration of competing interest}

The authors declare that they have no known competing financial interests or personal relationships that could have appeared to influence the work reported in this paper.

\section{References}

Ahmed, H., Davison, G., \& Dixon, D. (2017). Analysis of activity patterns, physiological demands and decision-making performance of elite futsal referees during matches. International Journal of Performance Analysis in Sport, 17(5), 737-751. https://doi. org/10.1080/24748668.2017.1399321.

Al-Haliq, M., Altahayneh, Z. L., \& Oudat, M. (2014). Levels of burnout among sports referees in Jordan. Journal of Physical Education and Sport, 14(1), 47-51. https://doi. org/10.7752/jpes.2014.01008.

Alarcon, F., Duran, G., \& Guajardo, M. (2014). Referee assignment in the Chilean football league using integer programming and patterns. International Transactions in Operational Research, 21(3), 415-438. https://doi.org/10.1111/itor.12049.

Aragão e Pina, J., Passos, A. M., Araújo, D., \& Maynard, M. T. (2018). Football refereeing: An integrative review. Psychology of Sport and Exercise, 35, 10-26. https://doi.org/ 10.1016/j.psychsport.2017.10.006.

Aragão e Pina, J., Passos, A. M., Carvalho, H., \& Maynard, M. T. (2019). To be or not to be an excellent football referee: Different experts' viewpoints. Journal of Sports Sciences, 37(6), 692-700. https://doi.org/10.1080/02640414.2018.1522940.

Araújo, D., \& Davids, K. (2016). Team synergies in sport: Theory and measures. Frontiers in Psychology, 7(SEP). https://doi.org/10.3389/fpsyg.2016.01449.

Araújo, D., Davids, K., \& Hristovski, R. (2006). The ecological dynamics of decision making in sport. Psychology of Sport and Exercise, 7(6), 653-676. https://doi.org/ 10.1016/j.psychsport.2006.07.002.

Baard, S. K., Rench, T. A., \& Kozlowski, S. (2015). Performance adaptation: A theoretical integration and review. Journal of Management, 40(1), 48-99. https://doi.org/ 10.1177/0149206313488210.

Bandura, A. (1997). Self-efficacy: The exercise of control. New York: W. H. Freeman.

Bartlett, M. S. (1951). The effect of standardization on a $\chi^{2}$ approximation in factor analysis. Biometrika, 38(3/4), 337-344. https://doi.org/10.2307/2332580.

Blickensderfer, E., Cannon-Bowers, J. A., \& Salas, E. (1997). Theoretical bases for team selfcorrection: Fostering shared mental models. In M. M. Beyerlein, D. A. Jackson, \& S. T. Beyerlein (Eds.), Advances in interdisciplinary studies of work teams (pp. 249-279). Greenwich, CT.

Boomsma, A. (2000). Reporting analyses of covariance structures. Structural Equation Modeling: A Multidisciplinary Journal, 7(3), 461-483. https://doi.org/10.1207/ S15328007SEM0703_6.

Boyer, S., MacMahon, C., Recopé, M., \& Rix-Lièvre, G. (2020). The assistant referees' activity in refereeing elite football: Preoccupations when not judging offside. Psychology of Sport and Exercise, 48, 101662. https://doi.org/10.1016/j. psychsport.2020.101662.

Boyer, S., Rix-Lièvre, G., \& Récopé, M. (2015). L'arbitrage de haut niveau, une affaire d'équipe. Movement \& Sport Sciences - Science \& Motricité, 101(87), 91-101. https:// doi.org/10.1051/sm/2014014.
Brannick, M. T., Chan, D., Conway, J. M., Lance, C. E., \& Spector, P. E. (2010). What is method variance and how can we cope with it? A panel discussion. Organizational Research Methods, 13, 407-420.

Burke, C. S., Stagl, K. C., Salas, E., Pierce, L., \& Kendall, D. (2006). Understanding team adaptation: A conceptual analysis and model. Journal of Applied Psychology, 91(6), 1189-1207. https://doi.org/10.1037/0021-9010.91.6.1189.

Buse, A. (1982). The likelihood ratio, Wald, and Lagrange multiplier tests: An expository note. The American Statistician, 36(3a), 153-157. https://doi.org/10.1080/ 00031305.1982 .10482817$.

Byrne, B. M. (2010). Structural equation modeling with AMOS (3rd ed.). New York, NY, USA: Routledge. https://doi.org/10.4324/9781410600219.

Callan, V. J., Terry, D. J., \& Schweitzer, R. (1994). Coping resources, coping strategies and adjustment to organizational change: Direct or buffering effects? Work \& Stress: An International Journal of Work, Health \& Organisations, 8(4), 372-383. https://doi. org/10.1080/02678379408256543.

Can, Y., Bayansalduz, M., Soyer, F., \& Pacali, S. (2014). Turkish adaptation of soccer referee decision satisfaction scale (SRDSS). Procedia - Social and Behavioral Sciences, 152, 756-760. https://doi.org/10.1016/j.sbspro.2014.09.316.

Cannon-Bowers, J. A., Salas, E., \& Converse, S. (1993). Shared mental models in expert team decision making. In N. J. Castellan (Ed.), Individual and group decision making: Current issues (pp. 221-246). Hillsdale, NJ, USA: Lawrence Erlbaum. https://doi.org/ 10.4324/9780203772744-20.

Catteeuw, P., Gilis, B., Jaspers, A., Wagemans, J., \& Helsen, W. F. (2010). Training of perceptual-cognitive skills in offside decision making. Journal of Sport and Exercise Psychology, 32(6), 845-861. https://doi.org/10.1123/jsep.32.6.845.

Collina, P. (2004). As minhas regras do jogo - O que o futebol me ensinou sobre a vida. Lisboa: Editorial Presença.

Cortina, J. M., Markell-Goldstein, H. M., Green, J. P., \& Chang, Y. (2019). How are we testing interactions in latent variable models? Surging forward or fighting shy? Organizational Research Methods, 109442811987253. https://doi.org/10.1177/ 1094428119872531.

Cosmin, D., \& Mircea, N. (2014). The development of futsal game at national level by implementing a strategic competitive and training management. Ovidius University Annals, Series Physical Educationa \& Sport/Science, Movement \& Health, XIV(2), 376-380.

Courtney, M. G. R. (2012). Determining the number of factors to retain in EFA: Using the SPSS R-Menu v2.0 to make more judicious estimations. Practical Assessment, Research and Evaluation, 18(8), 1-14.

Cunningham, I., Simmons, P., Mascarenhas, D., \& Redhead, S. (2014). Skilled interaction: Concepts of communication and player management in the development of sport officials. International Journal of Sport Communication, 7(2), 166-187. https://doi.org/10.1123/IJSC.2013-0098.

Cuskelly, G., \& Hoye, R. (2013). Sports officials' intention to continue. Sport Management Review, 16(4), 451-464. https://doi.org/10.1016/j.smr.2013.01.003.

Dechurch, L. A., \& Haas, C. D. (2008). Examining team planning through an episodic lens. Effects of deliberate, contingency, and reactive planning on team effectiveness. Small Group Research, 39(5), 542-568. https://doi.org/10.1177/ 1046496408320048.

Diotaiuti, P., Falese, L., Mancone, S., \& Purromuto, F. (2017). A structural model of selfefficacy in handball referees. Frontiers in Psychology, 8, 1-10. https://doi.org/ 10.3389/fpsyg. 2017.00811.

Dixon, D. (2014a). A pilot study of the physiological demands of futsal referees engaged in international friendly matches. American Journal of Sports Science and Medicine, 2 (3), 103-107. https://doi.org/10.12691/ajssm-2-3-7.

Dixon, D. (2014b). A retrospective study of the yo-yo IE2 test: Can it be used to differentiate between different levels of futsal referees? American Journal of Sports Science and Medicine, 2(3), 93-97. https://doi.org/10.12691/ajssm-2-3-5.

Dohmen, T., \& Sauermann, J. (2015). Referee bias. Journal of Economic Surveys, 1-17. https://doi.org/10.1111/joes.12106, 00(0).

Edwards, J. R. (2009). Seven deadly myths of testing moderation in organizational research. In C. E. Lance, \& R. J. Vandenberg (Eds.), Statistical and methodological myths and urban legends: Doctrine, verity and fable in the organizational and social sciences. New York, NY, USa: Routledge. https://doi.org/10.4324/978020386726614.

Eskiyecek, C. G., Satici, O., Ozaltas, H. N., Savucu, Y., \& Gul, M. (2019). An analysis on general self-efficacy beliefs of swimming referees in terms of demographic variables. Journal of Education and Learning, 8(5), 259-266. https://doi.org/10.5539/jel. v8n5p259.

Filho, E., \& Tenenbaum, G. (2012). Team mental models in sports: An overview. In R. Schinke (Ed.), Athletic insight's writings in sport psychology (sports and athletics preparation performance and psychology) (1st ed., pp. 329-342). Nova Science Pub Inc.

Finch, W. H., \& French, B. F. (2015). Latent variable modeling with R. New York, NY, USA: Routledge. https://doi.org/10.4324/9781315869797.

Finney, S. J., \& DiStefano, C. (2013). Non-normal and categorical data in structural equation modeling. In G. R. Hancock, \& R. O. Mueller (Eds.), Structural equation modeling: A second course (2nd ed., pp. 439-492). Charlotte, NC, USA: Information Age Publishing.

Finney, S. J., DiStefano, C., \& Kopp, J. P. (2016). Overview of estimation methods and preconditions for their application with structural equation modeling. In K. Schweizer, \& C. DiStefano (Eds.), Principles and methods of test construction: Standards and recent advances (pp. 135-165). Boston, MA, USA: Hogrefe Publishing. https://doi.org/10.1027/00449-000.

Futsal Laws of the Game. (2015). Zurich: Fédération Internationale de Football Association. 
Gorman, J. C., Cooke, N. J., \& Amazeen, P. G. (2010). Training adaptive teams. Human Factors: The Journal of the Human Factors and Ergonomics Society, 52(2), 295-307. https://doi.org/10.1177/0018720810371689.

Griffin, B., \& Hesketh, B. (2003). Adaptable behaviours for successful work and career adjustment. Australian Journal of Psychology, 55(2), 65-73. https://doi.org/10.1080/ 00049530412331312914.

Guillén, F., \& Feltz, D. L. (2011). A conceptual model of referee efficacy. Frontiers in Psychology, 2. https://doi.org/10.3389/fpsyg.2011.00025.

Guillén, F., Feltz, D. L., Gilson, T., \& Dithurbide, L. (2019). Psychometric properties of the Spanish version of the referee self-efficacy scale (REFS). Revista de Psicologia del Deporte, 28(1), 15-23.

Hancock, D. J., Martin, L. J., Evans, M. B., \& Paradis, K. F. (2018). Exploring perceptions of group processes in ice hockey officiating. Journal of Applied Sport Psychology, 30 (2), 222-240. https://doi.org/10.1080/10413200.2017.1349208.

Heggestad, E. D., Scheaf, D. J., Banks, G. C., Monroe Hausfeld, M., Tonidandel, S., \& Williams, E. B. (2019). Scale adaptation in organizational science research: A review and best-practice recommendations. Journal of Management, 45(6), 2596-2627. https://doi.org/10.1177/0149206319850280.

Helsen, W. F., \& Bultynck, J.-B. (2004). Physical and perceptual-cognitive demands of top-class refereeing in association football. Journal of Sport Sciences, 22(2), 179-189. https://doi.org/10.1080/02640410310001641502.

Hollenbeck, J. R., Ellis, A. P. J., Humphrey, S. E., Garza, A. S., \& Ilgen, D. R. (2011). Asymmetry in structural adaptation: The differential impact of centralizing versus decentralizing team decision-making structures. Organizational Behavior and Human Decision Processes, 114(1), 64-74. https://doi.org/10.1016/j.obhdp.2010.08.003.

Hoyle, R. H. (Ed.). (1995). Structural equation modeling: Concepts, issues and applications. Thousand Oaks, CA, USA: SAGE Publications.

Johns, G. (2006). The essential impact of context on organizational behavior. Academy of Management Review, 31(2), 386-408. https://doi.org/10.5465/amr.2006.20208687.

Jones, N. A., Ross, H., Lynam, T., Perez, P., \& Leitch, A. (2011). Mental models: An interdisciplinary synthesis of theory and methods. Ecology and Society, 16(1). https://doi.org/10.5751/ES-03802-160146.

Jorgensen, T. D., Pornprasertmanit, S., Schoemann, A. M., \& Rosseel, Y. (2019). semTools Useful tools for structural equation modeling (R package version 0.5-1.933) [Computer software].

Kaiser, H. F., \& Rice, J. (1974). Little jiffy, mark IV. Educational and Psychological Measurement, 34(1), 111-117. https://doi.org/10.1177/001316447403400115.

Karaçam, A., \& Pulur, A. (2017). Adaptation study of referee self-efficacy scale (REFS) to Turkish. Journal of Physical Education and Sports Sciences, 11(1), 118-128.

Kline, R. B. (2016). Principles and practice of structural equation modeling (4th ed.). New York, NY, USA: The Guilford Press.

Kozlowski, S. W. J., Toney, R. J., Mullins, M. E., Weissbein, D. A., Brown, K. G., \& Bell, B. S. (2001). Developing adaptability: A theory for the design of integratedembedded training systems. In E. Salas (Ed.), Advances in human performance and cognitive engineering research, 1 pp. 59-123). Amsterdam, Netherlands: Elsevier Science/JAI Press. https://doi.org/10.1016/S1479-3601(01)01004-9.

KPMG. (2016). Football clubs' valuation: The European elite 2016. Retrieved from https ://assets.kpmg.com/content/dam/kpmg/pdf/2016/05/the-european-elite-2016. pdf.

Labudek, S., Schweizer, G., Roth, A., Pizzera, A., Plessner, H., \& Brand, R. (2019). REFSD: A German scale for assessing referee self-efficacy. Zeitschrift für Sportpsychologie, 26(1), 15-24. https://doi.org/10.1026/1612-5010/a000256.

Laforge-MacKenzie, K., \& Sullivan, P. J. (2014). The relationship between self-efficacy and performance within a continuous educational gymnastics routine. Internationa Journal of Sport and Exercise Psychology, 12(3), 206-227. https://doi.org/10.1080/ 1612197X.2014.909511.

Laws of the game 2017/18. (2017). Zurich, Switzerland: The International Football Association Board. Retrieved from https://resources.fifa.com/mm/document/f ootballdevelopment/refereeing/02/90/11/67/lawsofthegame2017-2018-en_neutr al.pdf.

Lemon, J. (2006). Plotrix: A package in the red light district of R. $R$ News, 6(4), 8-12.

LePine, J. A. (2003). Team adaptation and postchange performance: Effects of team composition in terms of members' cognitive ability and personality. Journal of Applied Psychology, 88(1), 27-39. https://doi.org/10.1037/0021-9010.88.1.27.

LePine, J. A. (2005). Adaptation of teams in response to unforeseen change: Effects of goal difficulty and team composition in terms of cognitive ability and goal orientation. Journal of Applied Psychology, 90(6), 1153-1167. https://doi.org/ 10.1037/0021-9010.90.6.1153.

LePine, J. A., Piccolo, R. F., Jackson, C. L., Mathieu, J. E., \& Saul, J. R. (2008). A metaanalysis of teamwork processes: Tests of a multidimensional model and relationships with team effectiveness criteria. Personnel Psychology, 61(2), 273-307. https://doi. org /10.1111/j.1744-6570.2008.00114.x.

Lin, G. C., Wen, Z., Marsh, H. W., \& Lin, H. S. (2010). Structural equation models of latent interactions: Clarification of orthogonalizing and double-mean-centering strategies. Structural Equation Modeling, 17(3), 374-391. https://doi.org/10.1080/ 10705511.2010.488999.

Lirgg, C. D., Feltz, D. L., \& Merrie, M. D. (2016). Self-efficacy of sports officials: A critical review of the literature. Journal of Sport Behavior, 39, 39-50.

Londrina, D. A. R. D. E. (2018). Revista Brasileira de Futsal e Futebol, (43), 252-261.

Lüdecke, D. (2019). sjstats: Statistical functions for regression models ( $R$ package version 0.17.3. https://doi.org/10.5281/zenodo.1284472 [Computer software].

MacMahon, C., Helsen, W. F., Starkes, J. L., \& Weston, M. (2007). Decision-making skills and deliberate practice in elite association football referees. Journal of Sports Sciences, 25(1), 65-78. Retrieved from http://www.ncbi.nlm.nih.gov/pubmed $/ 17127582$.
Maddux, J. E. (1995). Self-efficacy theory: An introduction. In J. E. Maddux (Ed.), Selfefficacy, adaptation, and adjustment: Theory, research, and application (pp. 3-33). New York, NY: Plenum. https://doi.org/10.1007/978-1-4419-6868-5_1.

Mallo, J., Frutos, P. G., Juárez, D., \& Navarro, E. (2012). Effect of positioning on the accuracy of decision making of association football top-class referees and assistant referees during competitive matches. Journal of Sports Sciences, 30(13), 1437-1445. https://doi.org/10.1080/02640414.2012.711485.

Mallo, J., Navarro, E., Aranda, J. M. G., \& Helsen, W. F. (2009). Physical demands of topclass soccer assistant refereeing during high-standard matches. International Journal of Sports Medicine, 30(5), 331-336. https://doi.org/10.1055/s-0029-1202339.

Marks, M. A., Zaccaro, S. J., \& Mathieu, J. E. (2000). Performance implications of leader briefings and team interaction training for team adaptation to novel environments. Journal of Applied Psychology, 85(6), 971-986.

Marôco, J. (2014). In Análise de equações estruturais: Fundamentos teóricos, software \& aplicações (2nd ed.). Pêro Pinheiro, Portugal: ReportNumber.

Marôco, J. (2018). Análise estatística com o SPSS statistics (7th ed.). Pêro Pinheiro, Portugal: ReportNumber.

Marques-Quinteiro, P., Curral, L., Passos, A. M., \& Lewis, K. (2013). And now what do we do? The role of transactive memory systems and task coordination in action teams. Group Dynamics: Theory, Research, and Practice, 17(3), 194-206. https://doi.org/ 10.1037/a0033304.

Marques-Quinteiro, P., Ramos-Villagrasa, P. J., Passos, A. M., \& Curral, L. (2015). Measuring adaptive performance in individuals and teams. Team Performance Management: International Journal, 21(7/8), 339-360. https://doi.org/10.1108/ TPM-03-2015-0014.

Marsh, H. W., Wen, Z., \& Hau, K. T. (2004). Structural equation models of latent interactions: Evaluation of alternative estimation strategies and indicator construction. Psychological Methods, 9(3), 275-300. https://doi.org/10.1037/1082989X.9.3.275.

Mascarenhas, D., Collins, D., \& Mortimer, P. (2005a). Elite refereeing performance: Developing a model for sport science support. The Sport Psychologist, 19, 364-379.

Mascarenhas, D., Collins, D., \& Mortimer, P. (2005b). The accuracy, agreement and coherence of decision making in rugby union officials. Journal of Sport Behavior, 28, 253-271.

Mascarenhas, D., Collins, D., Mortimer, P. W., \& Morris, B. (2005). Training accurate and coherent decision making in rugby union referees. The Sport Psychologist, 19(2), 131-147. https://doi.org/10.1123/tsp.19.2.131.

Mascarenhas, D., O'Hare, D., \& Plessner, H. (2006). The psychological and performance demands of association football refereeing. International Journal of Sport Psychology, 37, 99-120.

Mathers, J., \& Brodie, K. (2011). Elite refereeing in professional soccer: A case study of mental skills support. Journal of Sport Psychology in Action, 2(3), 171-182. Retrieved from 10.1080/21520704.2011.609018.

Mathieu, J. E., Heffner, T. S., Goodwin, G. F., Salas, E., \& Cannon-Bowers, J. A. (2000). The influence of shared mental models on team process and performance. Journal of Applied Psychology, 85(2), 273-283. https://doi.org/10.1037/0021-9010.85.2.273.

Mathieu, J. E., \& Taylor, S. (2006). Clarifying conditions and decision points for mediational type inferences in Organizational Behavior. Journal of Organizational Behavior, 27, 1031-1056.

Maynard, M. T., Kennedy, D. M., \& Sommer, S. A. (2015). Team adaptation: A fifteenyear synthesis $(1998$ - 2013) and framework for how this literature needs to " adapt " going forward. European Journal of Work and Organizational Psychology, 24(5), 652-677. https://doi.org/10.1080/1359432X.2014.1001376.

McDonald, R. P., \& Ho, M.-H. R. (2002). Principles and practice in reporting structural equation analyses. Psychological Methods, 7(1), 64-82. https://doi.org/10.1037/ 1082-989X.7.1.64.

McEwan, D., \& Beauchamp, M. R. (2014). Teamwork in sport: A theoretical and integrative review. International Review of Sport and Exercise Psychology, 7(1), 229-250. https://doi.org/10.1080/1750984X.2014.932423.

McNamara, A., Arino de la Rubia, E., Zhu, H., Ellis, S., \& Quinn, M. (2018). skimr: Compact and flexible summaries of data (R package version 1.0.3) [Computer software].

Mohammed, S., Ferzandi, L., \& Hamilton, K. (2010). Metaphor no more: A 15-year review of the team mental model construct. Journal of Management, 36(4), 876-910. https://doi.org/10.1177/0149206309356804.

Mohammed, S., Klimoski, R., \& Rentsch, J. R. (2000). The measurement of team mental models: We have no shared schema. Organizational Research Methods, 3(2), 123-165. https://doi.org/10.1177/109442810032001.

Moore, R., Bullough, S., Goldsmith, S., \& Edmondson, L. (2014). A systematic review of futsal literature. American Journal of Sports Science and Medicine, 2(3), 108-116. https://doi.org/10.12691/ajssm-2-3-8.

Moritz, S. E., Feltz, D. L., Fahrbach, K. R., Mack, D. E., Moritz, S. E., Feltz, D. L., Mack, E. (2013). The relation of self-efficacy measures to sport performance: A metaanalytic review. Research Quarterly for Exercise and Sport, 71(3), 280-294. https:// doi.org/10.1080/02701367.2000.10608908.

Myers, N. D., Feltz, D. L., Guillén, F., \& Dithurbide, L. (2012). Development of, and initial validity evidence for, the referee self-efficacy scale: A multistudy report. Journal of Sport and Exercise Psychology, 34(6), 737-765. https://doi.org/10.1123/ jsep.34.6.737.

Nazarudin, M. N., Abdullah, M. R., Omar Fauzee, M. S., Abdullah, N. M., Noordin, H., \& Suppiah, P. K. (2014). Psychological skills assessment and referee rugby sevens performance. Journal of Educational Thinkers, 5, 165-184.

Nizam, M., Noordin, H., Suppiah, P. K., Razali, M., Fauzee, M. S. O., \& Meera Abdullah, N. (2014). Psychological skills assessment and referee rugby sevens performance. Journal for Education Thinkers, 5(9), 165-184.

Nunes, R., Schwarzer, R., \& Jerusalem, M. (1999). A escala de autoeficácia geral percecionada. Retrieved from http://userpage.fu-berlin.de/ health/auto.htm. 
Perreau-Niel, A., \& Erard, C. (2015). French football referees: An exploratory study of the conditions of access and employment for referees in terms of level and gender. Soccer and Society, 16(1), 1-16. https://doi.org/10.1080/14660970.2012.627168.

Peters, G.-J. Y. (2018). userfriendlyscience: Quantitative analysis made accessible (R package version 0.7.2. https://doi.org/10.17605/osf.io/txequ [Computer software].

Pizzera, A., \& Raab, M. (2012). Does motor or visual experience enhance the detection of deceptive movements in football? International Journal of Sports Science and Coaching, $7(2), 269-283$.

Plessner, H., \& MacMahon, C. (2013). The sports official in research and practice. In D. Farrow, J. Baker, \& C. MacMahon (Eds.), Developing sport expertise: Researchers and coaches put theory into practice (pp. 172-192). New York: Routledge.

Praschinger, A., Pomikal, C., \& Stieger, S. (2011). May I curse a referee? Swear words and consequences. Journal of Sports Science and Medicine, 10(2), 341-345.

Pulakos, E. D., Schmitt, N., Dorsey, D. W., Arad, S., Borman, W. C., \& Hedge, J. W. (2002). Predicting adaptive performance: Further tests of a model of adaptability. Human Performance, 14(4), 299-323. https://doi.org/10.1207/ S15327043HUP1504_01.

R Core Team. (2019). R: A language and environment for statistical computing (version 3.6.1). Vienna, Austria: R Foundation for Statistical Computing [Computer software].

Randall, K. R., Resick, C. J., \& DeChurch, L. A. (2011). Building team adaptive capacity: The roles of sensegiving and team composition. Journal of Applied Psychology, 96(3), 525-540. https://doi.org/10.1037/a0022622.

Raykov, T. (2001). Estimation of congeneric scale reliability using covariance structure analysis with nonlinear constraints. British Journal of Mathematical and Statistical Psychology, 54, 315-323. https://doi.org/10.1348/000711001159582.

Rebelo, A. N., Ascensão, A. A., Magalhães, J. F., Bischoff, R., Bendiksen, M., \& Krustrup, P. (2011). Elite futsal refereeing: Activity profile and physiological demands. Journal of Strength and Conditioning Research, 25(4), 980-987.

Resick, C. J., Dickson, M. W., Mitchelson, J. K., Allison, L. K., \& Clark, M. A. (2010). Team composition, cognition, and effectiveness: Examining mental model similarity and accuracy. Group Dynamics: Theory, Research, and Practice, 14(2), 174-191. https://doi.org/10.1037/a0018444.

Resick, C. J., Murase, T., Bedwell, W. L., Sanz, E., Jimenez, M., \& DeChurch, L. A. (2010) Mental model metrics and team adaptability: A multi-facet multi-method examination. Group Dynamics: Theory, Research, and Practice, 14, 332-349. https:// doi.org/10.1037/a0018822.

Revelle, W. (2019). psych: Procedures for psychological, psychometric, and personality research (R package version 1.9.4). Evanston, IL: Northwestern University [Computer software].

Rosen, M.a., Bedwell, W. L., Wildman, J. L., Fritzsche, B.a., Salas, E., \& Burke, C. S. (2011). Managing adaptive performance in teams: Guiding principles and behavioral markers for measurement. Human Resource Management Review, 21(2), 107-122. https://doi.org/10.1016/j.hrmr.2010.09.003.

Rosseel, Y. (2012). lavaan: An R package for structural equation modeling. Journal of Statistical Software, 48(2), 1-21. https://doi.org/10.18637/jss.v048.i02.

Rouse, W. B., Cannon-Bowers, J. A., \& Salas, E. (1992). The role of mental models in team performance in complex systems. IEEE Transactions on Systems Man and Cybernetics, 22(6), 1296-1308. https://doi.org/10.1109/21.199457.

RStudio Team. (2019). RStudio: Integrated development for $R$ (version 1.2.1330). Boston, MA, USA: RStudio, Inc [Computer software].

Ruscio, J. (2018). RGenData: Generates multivariate nonnormal data and determines how many factors to retain (R package version 1.0) [Computer software].
Ruscio, J., \& Roche, B. (2012). Determining the number of factors to retain in an exploratory factor analysis using comparison data of known factorial structure. Psychological Assessment, 24(2), 282-292. https://doi.org/10.1037/a0025697.

Samuel, R. D. (2015). A psychological preparation framework for elite soccer referees: A practitioner's perspective. Journal of Sport Psychology in Action, 0704, (November), 1-18. https://doi.org/10.1080/21520704.2015.1065938.

Santos, C. M., Passos, A. M., \& Uitdewilligen, S. (2016). When shared cognition leads to closed minds: Temporal mental models, team learning, adaptation and performance. European Management Journal, 34(3), 258-268. https://doi.org/10.1016/j. emj.2015.11.006.

Santos, C. M., Uitdewilligen, S., \& Passos, A. M. (2015). Why is your team more creative than mine? The influence of shared mental models on intra-group conflict, team creativity and effectiveness. Creativity and Innovation Management, 24(4), 645-658. https://doi.org/10.1111/caim.12129.

Sarstedt, M., Hair, J. F., Nitzl, C., Ringle, C. M., \& Howard, M. C. (2020). Beyond a tandem analysis of SEM and PROCESS: Use of PLS-SEM for mediation analyses! International Journal of Market Research, 147078532091568. https://doi.org/ $10.1177 / 1470785320915686$.

Signorell, A., Aho, K., Alfons, A., Anderegg, N., Aragon, T., Arppe, A., ... Zeileis, A. (2019). DescTools: Tools for descriptive statistics ( $R$ package version 0.99.28) [Computer software].

Slack, L. A., Maynard, I. W., Butt, J., \& Olusoga, P. (2013). Factors underpinning football officiating excellence: Perceptions of English premier league referees. Journal of Applied Sport Psychology, 25(3), 298-315. https://doi.org/10.1080/ 10413200.2012.726935.

Slack, L. A., Maynard, I. W., Butt, J., \& Olusoga, P. (2015). An evaluation of a mental toughness education and training program for early-career English football league referees. The Sport Psychologist, 29(3), 237-257. https://doi.org/10.1123/tsp.20140015 .

Smith-Jentsch, K. A., Cannon-Bowers, J., Tannenbaum, S. I., \& Salas, E. (2008). Guided team self-correction impacts on team mental models. Small Group Research, 39(3), 303-327.

Svantesson, D. (2014). Could technology resurrect the dignity of the FIFA World Cup refereeing? Computer Law \& Security Report, 30(5), 569-573. https://doi.org/ 10.1016/j.clsr.2014.07.004.

Unkelbach, C., \& Memmert, D. (2008). Game management, context effects, and calibration: The case of yellow cards in soccer. Journal of Sport and Exercise Psychology, 30(1), 95-109. Retrieved from http://www.scopus.com/inward/record. url?eid=2-s2.0-44649144574\&partnerID $=40 \& \mathrm{md} 5=9 \mathrm{c} 661 \mathrm{eb} 49649610 \mathrm{~b} 04 \mathrm{c} 8637$ f5594feb9.

Webb, T. (2016). 'Knight of the whistle': W.P. Harper and the impact of the media on an association football referee. International Journal of the History of Sport, 33(3), 306-324. https://doi.org/10.1080/09523367.2016.1151004.

Webb, T., \& Thelwell, R. (2015). "He's taken a dive" Cultural comparisons of elite referee responses to reduced player behaviour in association football. Sport, Business and Management: International Journal, 5(3), 242-258. https://doi.org/10.1108/SBM-042014-0019.

Webb, T., Wagstaff, C. R. D., Rayner, M., \& Thelwell, R. (2016). Leading elite association football referees: Challenges in the cross-cultural organization of a geographically dispersed group. Managing Sport and Leisure, 21(3), 105-123. https://doi.org/ $10.1080 / 23750472.2016 .1209978$.

Weston, M., Drust, B., Atkinson, G., \& Gregson, W. (2011). Variability of soccer referees match performances. International Journal of Sports Medicine, 32(3), 190-194. 